\title{
MAPEAMENTO DA PLANÍCIE COSTEIRA E MORFOLOGIA E DINÂMICA DAS PRAIAS DO MUNICÍPIO DE ITAPOÁ, ESTADO DE SANTA CATARINA: SUBSÍDIOS À OCUPAÇÃO

\author{
MARIA CRISTINA DE SOUZA*
}

\author{
DISSERTAÇÃO DE MESTRADO - Programa de Pós-Graduação em Geologia - UFPR \\ DATA DE DEFESA: 28/04/99
}

\begin{abstract}
O objetivo deste trabalho é contribuir para a compreensão da dinâmica costeira e fornecer subsídios para o planejamento e ocupação da orla litorânea do Município de Itapoá, litoral norte do Estado de Santa Catarina. Para compreender a dinâmica costeira em diversas escalas temporais, o trabalho foi dividido em três partes: i) mapeamento da planície costeira e evolução geológica durante o Quaternário ii) caracterização da morfologia e dinâmica das praias; iii) análise das variações da linha de costa nas últimas quatro décadas. O mapa da planície costeira é apresentado na escala 1: 50.000. No mapeamento foi dada ênfase às unidades do Quater-nário costeiro e à identificação de ambientes de sedimentação. Também, foram identificados e datados indicadores
\end{abstract}

de paleoníveis marinhos holocênicos. A caracterização das praias foi realizada através de: i) levantamentos sazonais de nove perfis planialtimétricos durante dois anos; ii) caracterização sedimentológica através de amostragens longitudinais e transversais; iii) classificação morfodinâmica com base nos modelos existentes na bibliografia. A análise das variações da linha de costa foi realizada através da comparação de fotografias aéreas verticais dos anos de 1957, 1978 e 1995. Com base nos resultados obtidos foram apresentadas algumas sugestões e recomendações com o objetivo de minimizar os problemas decorrentes da interação entre a dinâmica costeira e a ocupação antrópica da orla litorânea do Município de Itapoá.

*E-mail: cristina@geologia.ufpr.br 